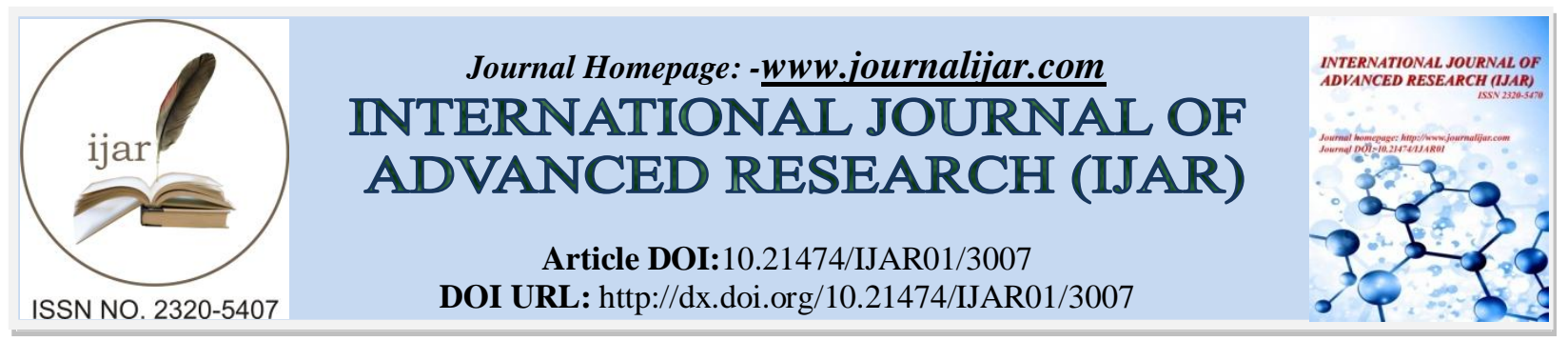

RESEARCH ARTICLE

\title{
HYPOTHALAMIC CAVERNOMA IN A 28 YEARS OLD SAUDI LADY: CASE REPORT
}

\section{Naif Edah Alomairi.}

Assistant professor of neurology, Head of Internal Medicine Department, College of Medicine - Taif University, Saudi Arabia.

\section{Manuscript Info}

Manuscript History

Received: 28 November 2016

Final Accepted: 27 December 2016

Published: January 2017

Key words:-

Vascularmalformation,cavernoma,angio ma,haemangioma.

\section{Abstract}

Background:Cerebral vascular malformations occur in $0.1-4 \%$ of the general population.Cavernoma is a subtype of these malformations with $0.4 \%$ incidence rate.Symptoms vary from absence to various neurological sequelae.We believe it's important to report this case because it strongly emphasizes that patients should not be profiled, and chronic complaints may need reassessment.

Case Presentation:We report a case of 28-years old Saudi ladywith cerebral cavernoma. She is complaining ofchronic headache for five years with recurrent attacks of severe headache for the last two years.

Conclusion:Cavernoma is the least common vascular malformation in central nervous system which may cause serious complications.Decision about management depends on whether it is symptomatic or not.Hence,patients should be evaluated carefully and chronic complaints should always be revisited.

Copy Right, IJAR, 2016,. All rights reserved.

\section{Introduction:-}

Cavernous malformations are also referred to as cavernous angiomas,cavernous haemangiomas or cavernomas.It occurs sporadically or in a familial pattern. ${ }^{(1)}$ It is the least common cerebral vascular malformation with an incidence rate $0.4 \%$ of the general population. ${ }^{(2,3)}$ Symptoms are related to its site,size,venous drainage and association with other malformations. We present a patient with history of chronic headache. She presented to our emergency department with worsening of that headache for three days and was found to have a leaking cerebral cavernoma. This case asserts that chronic complaints may need reassessment.

\section{Case Presentation:-}

The patient is a 28 -year old Saudi lady presented with an attack of severe headache,associated with nausea,vomiting and blurring of vision for three days. It is occipital, of thunderclap nature and occurs in several episodes daily.Each lasts for minutes and associated with symptoms of meningism.

These attacks started two years back with a frequency of one every 4-5 months.Frequency and severity were increasing recently.

She has five years history of chronic headache which was diagnosed as migraine and cerebral venous thrombosis(received anticoagulant for a year). 
There are no other neurological symptoms and she has no other medical problems or receiving any regular medications.Family history is positive for epilepsy(maternal aunt and uncle). She is married with three kids and has no special habits.

On examination, the patient had an average built,general and systemic examination were normal.

Full neurological examination came normal apart from ophthalmological exam which showed:

$>$ Pupils:equal and reactive with relative afferent pupillary defect(RAPD) more in left eye.

$>$ Visual acuity: Right eye:20/25,Left eye:20/30.

$>$ Extra ocular movements(EOMs):normal eye movements in all directions.

$>$ Fundi:Bitemporal optic atrophy.(Figure 1)

$>$ Visual fields: Binasal hemianopia. (Figure 2)

$>$ Her blood tests were normal.

$>$ Magnetic Resonance Image (MRI) (Figure 3), Magnetic Resonance Venography (MRV) and Magnetic Resonance Angiography (MRA) brain are done.

Figure 1:-Fundus examination showing bitemporal optic atrophy.
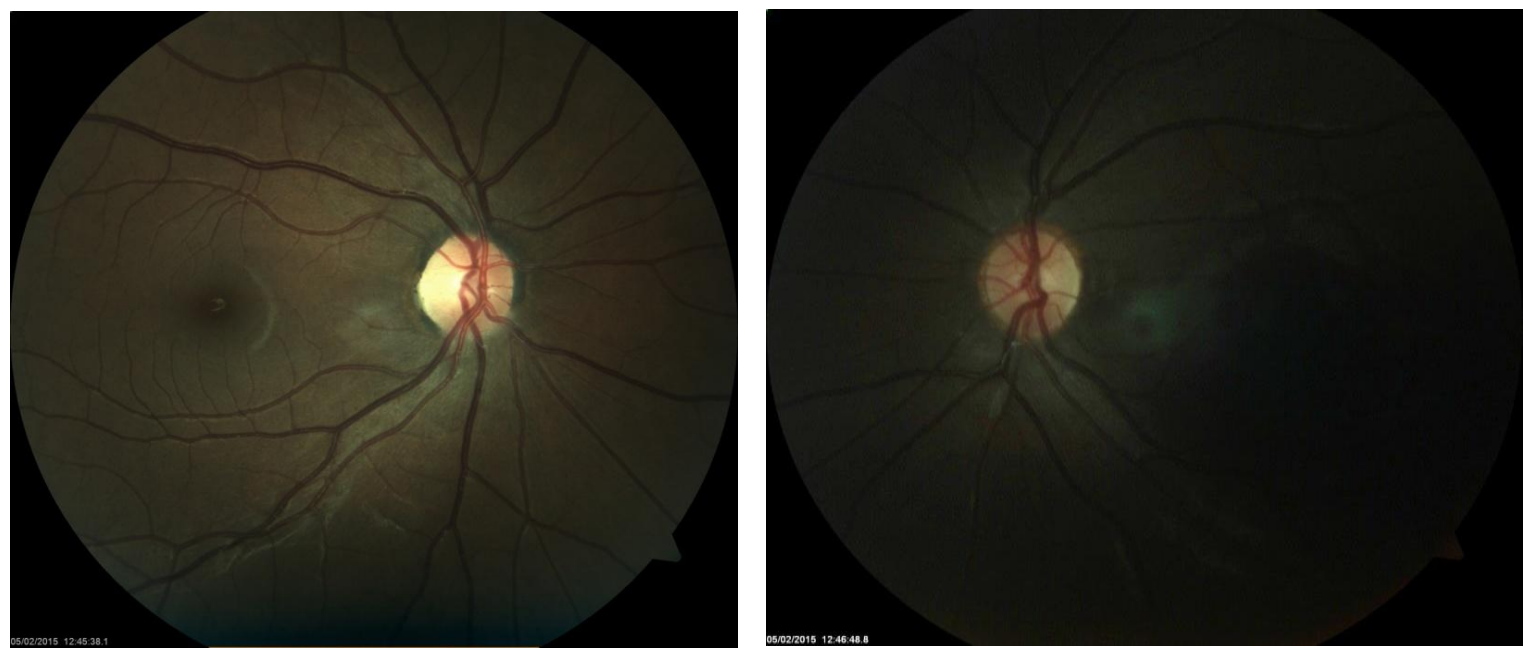

Figure 2:-Visual fields show loss of nasal fields.
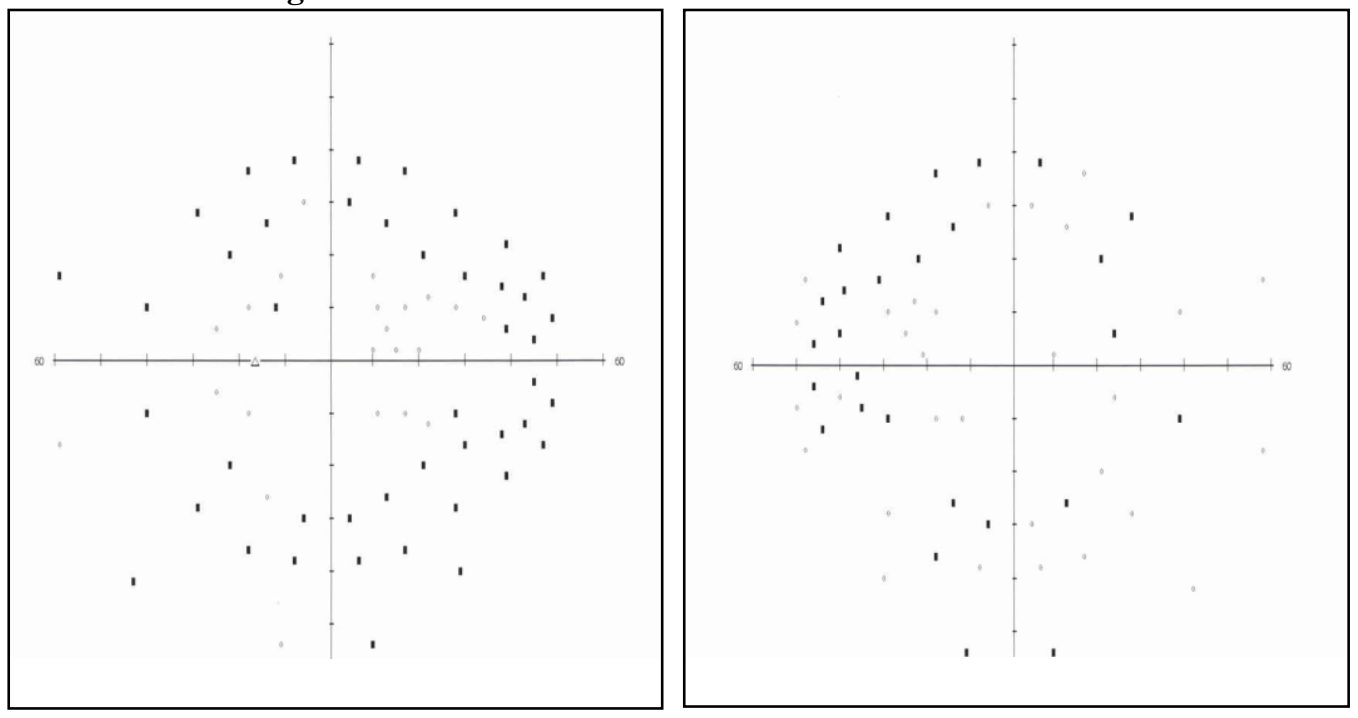
Figure 3:-MRI shows Hypothalamic Cavernoma, Popcorn apperance (yellow and red arrows)
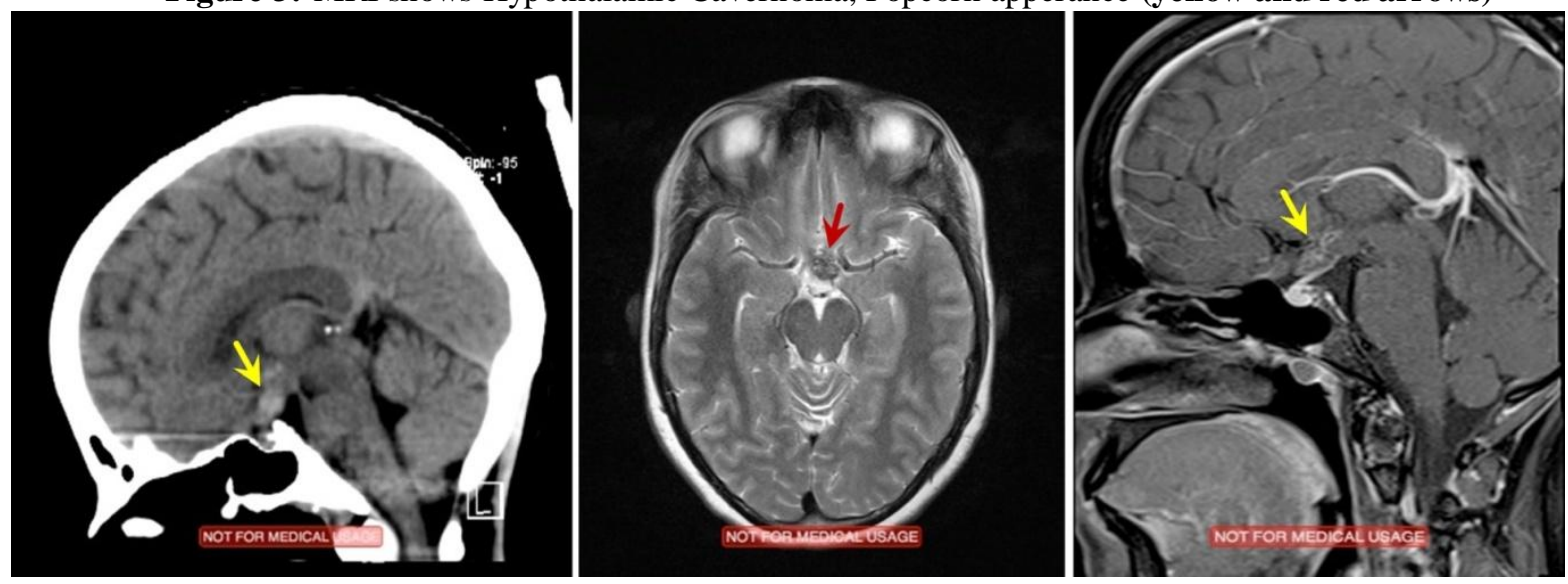

\section{Discussion:-}

Cerebral vascular malformations occur in 0.1 to 4.0 percent of the general population. Four general subtypes of congenital malformations have been described:developmental venous anomalies,capillary telangiectasias,cavernous malformations and arteriovenous malformations. ${ }^{(2,3)}$

Three genetic loci (CCM1, CCM2, and CCM3) responsible for familial cavernous malformations (CMs) have been reported. ${ }^{(4-6)}$

The cerebrum is the most common location for CMs $(70-90 \%) \cdot{ }^{(7)}$ They have been reported throughout the supratentorial compartment, but most commonly are subcortical and inclined to the rolandic and temporal areas. Posterior fossa lesions involve approximately 25 percent of CMs in most large series, with the majority located in the pons and cerebellar hemispheres. There have beenjust 36 cases of spinal cord cavernous malformations announced in the literature. ${ }^{(8)}$

Supratentorial CMs commonly present with hemorrhage, seizures, and progressive neurologic deficits. This may be the result of mass effect and secondary compromise of the microcirculation, or of microhemorrhages with local hemosiderin deposition irritating cortical or subcortical tissue. Annual bleeding rates of 0.25 to 1.1 percent have been reported. ${ }^{(9,10)}$

Infratentorial CMs commonly present with hemorrhage and progressive neurologic deficits. The lesions of brainstemis worse than that in other areas. The annual bleeding rate for brainstem lesions is 2 to 3 percent per year, with recurrent hemorrhage rates approaching 17 to 21 percent $^{(11)}$ Progressive neurologic decline is observed in 39 percent.

The natural history of asymptomatic lesions is significantly different from CMs presenting with clinical sequelae. $50 \%$ of 122 patients (age ranged from $4-82$ years and mean 37 years). ${ }^{(12)}$ on follow up mean of 34 months, the hemorrhage rate in the asymptomatic patients was $0.6 \%$ and $4.5 \%$ in the symptomatic patients. In another cohort, five year rates of hemorrhage were 2.4 percent for a first hemorrhage and 29 percent for a recurrent hemorrhage. ${ }^{(13)}$ The risk of recurrent hemorrhage declines over time. ${ }^{(13,14)}$ While prior hemorrhage is a consistent risk factor for subsequent hemorrhage, studies have found inconsistent results as to other risk factors for hemorrhage and neurologic disability, including gender, lesion size, location, and multiplicity. ${ }^{(12-15)}$

CMsblood flowis low. Therefore, they usually are indicated to as "angiographically occult", due to may not be seen on angiography. MRI usually establishes the diagnosis. Characteristic findings on T-1 and T-2 weighted images include a "popcorn" pattern of variable image intensities consistent with evolving blood products. A dark hemosiderin ring, best seen on T2 or gradient echo sequences at the periphery of the lesion, is suggestive of remote hemorrhage. ${ }^{(16)}$ 
Computed tomography usually demonstrates a nonspecific, irregular, hyperdense mass with variable degrees of calcification. Angiography demonstrates a capillary blush or early draining vein in approximately 10 percent of patients . Digital subtraction angiography appears to be much more sensitive than MRI for detecting the presence of $\mathrm{CM}$-associated atypical venous drainage. ${ }^{(17)}$

Asymptomatic CMs are observed, irrespective of location. Surgical resection indications of accessible symptomatic lesionsof cerebral and cerebellum include progressive neurologic deficit, intractable epilepsy, and recurrent hemorrhage ${ }^{(18-19)}$ Patients with symptomatic CMs entirely surrounded by eloquent tissue (e.g., rolandic cortex, brainstem, thalamus/basal ganglia) are usually observed despite the poor natural history associated with untreated brainstem and thalamic lesions.

In our case,first MRI,MRV done five years ago showed the suprasellar lesion. However, her normal variant hypoplastic transverse sinus made her diagnosed as cerebral venous thrombosis in presence of headache and bilateral papilledema .She continued on anticoagulant for one year. Since that time she has chronic headache which is considered migraine and treated for migraine headache.

During one of her attacks of severe headache She presented to our emergency department and was associated with nausea, blurring of vision and symptoms of meningism. On examination,we found her discs abnormality which is confirmed by fundus photography and visual fields. We revised her images again and new one is done(Figure 3). We conclude that she has never cerebral venous thrombosis and this is a normal variant of hypoplastic transverse sinus.Moreover ,she has progressive neurological deficit which is bilateral optic atrophy due to compression of the optic chiasma by the lesion.Leaking from the cavernoma is the cause of her intractable headache due to meningeal irritation. CSF xanthochromia was checked and confirm the leaking Accordingly, we referred the patient to the neurosurgery team.

\section{Conclusion:-}

Cavernous malformations are the least common vascular anomaly of central nervous system.It may be asymptomatic or cause various neurological deficits.

Surgical intervention is recommended only if it is symptomatic.

This case reminds us how serious diseases can masquerade in old complaints. Patients should never be profiled and chronic complaints should always be revisited.

\section{References:-}

1. Rigamonti D, Hardley MN, Drayer BP, et al.Cerebral cavernous malformations.Incidence and familial occurrence.NEngl J Med 1988;319:343.

2. McCormick, WF. Pathology of vascular malformations of the brain. In: Intracranial Arteriovenous Malformations,Wilson, CB, Stein, BM(Eds), William\&Wilkins,Baltimore, MD 1984. p.44.

3. Russell, DS, Rubinstein, LJ. Pathology of Tumours of the Nervous System. $5^{\text {th }}$ ed. William\&Wilkins,Baltimore, MD 1989. p.727.

4. Dubovsky J, Zabramski JM, Kurth J, et al.A gene responsible for cavernous malformations of the brain maps to chromosome 79.Hum Mol Genet 1995; 4:453.

5. Laberge-Le Couteulx S, Jung HH, Labauge P, et al.Truncating mutations in CCM1, encoding KRIT1, cause hereditary cavernous angiomas.Nat Genet 1999; 23:189.

6. Verlaan DJ, Davenport WJ, Stefan H, et al.Cerebral cavernous malformations:mutations in Krit1.Neurology 2002; 58:853.

7. Mc Cormick, PC, Michelson, WJ. Management of intracranial cavernous and venous malformations.In: Intracranial vascular malformations, Barrow, DL(Ed), American Association of Neurological Surgeons. Park Ridge, IL 1990.P.197.

8. Tew, JM, Sathi, S. Cavernous Malformations.In: Primer on Cerebrovascular Diseases, Welch, KM, Caplan, LR, Reis, DJ, et al.(Eds), Academic Press. San Diego, CA 1997. P.550.

9. Robinson JR, Awad IA, Little JR. Natural history of the cavernous angioma. J Neurosurg 1991; 75:709.

10. Aiba T, Tanaka R, Koike T, et al. Natural history of intracranial cavernous malformations. J Neurosurg 1995; 83:56. 
11. Fritschi JA, Reulen HJ, Spetzler RF, Zabramski JM. Cavernous malformations of the brain stem. A review of 139 cases. ActaNeurochir(Wien)1994;130:35.

12. Kondziolka D, Lunsford LD, Kestle JR. The natural history of cerebral cavernous malformations. J Neurosurg 1995;83:820.

13. AL-Shahi Salman R, Hall JM, Home MA, et al. Untreated clinical course of cerebral cavernous malformations: a prospective,population-based cohort study. Lancet Neurol 2012;11:217.

14. Flemming KD, Link MJ, Christianson TJ, Brown RD Jr. Prospective haemorrhage risk of intracerebral cavernous malformations. Neurology 2012;78:632.

15. Robinson JR jr, Awad IA, Magdinec M, Paranandi L. Factors predisposing to clinical disability in patients with cavernous malformations of the brain. Neurosurgery 1993; 32:730.

16. Rigamonti D, Hadley MN, Drayer BP, et al. Cerebral cavernous malformations. Incidence and familial occurrence. N Engl J Med 1988; 319:343.

17. Kamezawa T, Hamada J, Niiro M, et al. Clinical implications of associated venous drainage in patients with cavernous malformations. J Neurosurg 2005; 102:24.

18. Baumann CR, Acciarri N, Bertalanffy H, et al. Seizure outcome after resection of supratentorial cavernous malformations: a study of 168 patients. Epilepsia 2007; 48:559.

19. Cohen DS, Zubay GP, Goodman RR. Seizure outcome after lesionectomy for cavernous malformations. J Neurosurg 1995; 83:237. 